\title{
Heating ability and biocompatibility study of silica-coated magnetic nanoparticles as heating mediators for magnetic hyperthermia and magnetically triggered drug delivery systems
}

\author{
MEYSAM SOLEYMANI and MOHAMMAD EDRISSI* \\ Department of Chemical Engineering, Amirkabir University of Technology, Hafez Ave., 15875-4413 Tehran, Iran
}

MS received 5 June 2015; accepted 24 June 2015

\begin{abstract}
The aim of this study is to prepare core-shell $\mathrm{La}_{0.73} \mathrm{Sr}_{0.27} \mathrm{MnO}_{3}$-silica nanoparticles and evaluating their heat generation ability under the safe alternating magnetic field $\left(f=100 \mathrm{kHz}\right.$ and $\left.H=10-20 \mathrm{kA} \mathrm{m}^{-1}\right)$ for potential applications in magnetic fluid hyperthermia and magnetically triggered drug delivery systems. The magnetic cores of $\mathrm{La}_{0.73} \mathrm{Sr}_{0.27} \mathrm{MnO}_{3}$ with an average particle size of $54 \mathrm{~nm}$ were synthesized by the citrate-gel method. Then, the Stober method was applied to encapsulate nanoparticles with 5-nm-thick silica shell. The core-shell structure of nanoparticles was confirmed by $\mathrm{X}$-ray diffraction, fourier transform infrared spectroscopy and transmission electron microscopy analyses. Cytotoxicity of bare and silica-coated nanoparticles was evaluated by methyl thiazol tetrazolium bromide assay with MCF-7 cell line. The results revealed that the both samples have negligible toxicity below $500 \mu \mathrm{g} \mathrm{ml}^{-1}$ and silica coating can improve the biocompatibility of nanoparticle. In addition, calorimetric measurements were used to determine the heating efficiency of the core-shell nanostructures in aqueous medium. The results showed that the heat generated of the prepared sample could be safely controlled in the range of $40-60^{\circ} \mathrm{C}$ which is suitable for biomedical applications.
\end{abstract}

Keywords. Hyperthermia; core-shell; magnetic nanoparticles; biocompatibility; Stober method.

\section{Introduction}

Nowadays, magnetic nanoparticles (MNPs), due to their particular physicochemical properties, have attracted growing interest in biomedicine and bioengineering such as magnetically triggered drug delivery, ${ }^{1}$ bio-separation, ${ }^{2,3}$ magnetic resonance imaging, ${ }^{4}$ biomacromolecule purification ${ }^{5}$ and magnetic hyperthermia. ${ }^{6,7}$ Magnetic hyperthermia has long been used as a treatment option for cancer. ${ }^{8}$ In this method MNPs are introduced to the tumour tissue and then exposed to an alternating magnetic field (AMF). This method leads to heat generation by the MNPs which can kill the cancerous cells. ${ }^{6,7}$ In magnetically triggered drug delivery systems, MNPs are normally coated with a thermosensitive polymer as drug carrier. When these MNPs are exposed to an $\mathrm{AMF}$, due to the heat generated by magnetic core, phase transition occurs in the thermosensitive polymer and drug releases. ${ }^{9}$ The most common MNPs used for magnetic hyperthermia or drug delivery are $\mathrm{Fe}_{3} \mathrm{O}_{4}$ or $\gamma-\mathrm{Fe}_{2} \mathrm{O}_{3} .{ }^{10-12}$ However, their use as heat generating agent is associated with a main drawback in related to the lack of in vivo control on the temperature of nanoparticles, which can cause local overheating and damage to surrounding healthy cells.

To overcome this problem, first option is monitoring temperature of tissue using an invasive thermometry to control the temperature by adjusting the AMF intensity. Another

*Author for correspondence (edrisi@aut.ac.ir) option is to take advantage of Curie temperature $\left(T_{\mathrm{c}}\right.$, temperature at which MNPs lose their magnetic properties) of MNPs as an intrinsic thermo-regulating property. Hence, the overheating can be hindered due to the change in the magnetic state of nanoparticles in the vicinity of the $T_{\mathrm{c}} \cdot{ }^{13}$ Hence, by employing MNPs with $T_{\mathrm{c}}$ in the desired temperature range, the maximum attained temperature by MNPs can be controlled even with unwanted changes in magnetic field intensity. $\mathrm{La}_{1-x} \mathrm{Sr}_{x} \mathrm{MnO}_{3}$ perovskite oxides with adjustable $T_{\mathrm{c}}$ in the body temperature range for $0.2 \leq x \leq 0.3$ are one of the particular interests for biomedical application. ${ }^{14}$ Among the series of $\mathrm{La}_{1-x} \mathrm{Sr}_{x} \mathrm{MnO}_{3}$ perovskite oxides the $\mathrm{La}_{0.73} \mathrm{Sr}_{0.27} \mathrm{MnO}_{3}$ possesses highest saturation magnetization with $T_{\mathrm{c}}$ of about $70-80^{\circ} \mathrm{C}$. Hence it is more suitable for biomedical application among all $\mathrm{La}_{1-x} \mathrm{Sr}_{x} \mathrm{MnO}_{3}$ compounds. In order to prevent toxic effects of MNPs, the surface of nanoparticles is generally coated with an organic layer (polymer or surfactants) or inorganic layer (silica, carbon or precious metals) or combination of them. ${ }^{15-19}$ Among various protective coatings, silica possesses several advantages as a coating shell for MNPs. The formation of silica shell on the surface of MNPs could hinder the magnetic dipolar attraction between particles, which improves their dispersibility and chemical stability in aqueous media and biological systems. Another advantage of silica coating is that the silanol or siloxane groups present on the surface of silica shell may be modified with various functional groups such as amines and carboxyl groups. ${ }^{20-22}$ 
In this research we focused on the preparation of MNPs based on $\mathrm{La}_{0.73} \mathrm{Sr}_{0.27} \mathrm{MnO}_{3}$ (LSMO) as the self-controlled heating core and silica shell as protective layer which can be easily functionalized with targeting and drug releasing components. Cytotoxicity of bare and silica-coated nanoparticles was evaluated by MTT assay with MCF-7 cell line. Calorimetric measurements were then carried out to determine their ability for heat generation under the safe and harmless AFM ( $H=10-20 \mathrm{kA} \mathrm{m}^{-1}, f=100 \mathrm{kHz}$ ) used in our study.

\section{Materials and methods}

\subsection{Materials}

$\mathrm{La}\left(\mathrm{NO}_{3}\right)_{3} \cdot 6 \mathrm{H}_{2} \mathrm{O}$ (Sigma), $\mathrm{Sr}\left(\mathrm{NO}_{3}\right)_{3}$ (Merck), $\mathrm{Mn}\left(\mathrm{NO}_{3}\right)_{2}$. $4 \mathrm{H}_{2} \mathrm{O}$ (Merck), citric acid $\left(\mathrm{C}_{6} \mathrm{H}_{8} \mathrm{O}_{7}\right.$, Merck), ethylene glycol $\left(\mathrm{C}_{2} \mathrm{H}_{6} \mathrm{O}_{2}\right.$, Merck), tetraethylorthosilicate (TEOS), methanol, ethanol and ammonia solution $\left(\mathrm{NH}_{4} \mathrm{OH}, 25 \mathrm{wt} \%\right.$, Merck) were all used as supplied without further purification.

\subsection{LSMO nanoparticles synthesis}

The citrate-gel method with optimized quantities was applied to synthesize the LSMO nanoparticles. ${ }^{23-25}$ The metal nitrates were used as starting materials and weighed according to the stoichiometric composition of $\mathrm{La}_{0.73} \mathrm{Sr}_{0.27} \mathrm{MnO}_{3}$ and dissolved in deionized water. The prepared solution was mixed with citric acid and ethylene glycol and then aqueous ammonia was added dropwise to adjust $\mathrm{pH}$ of solution to 9 . The solution was then heated on a hot plate under constant stirring at $75-80^{\circ} \mathrm{C}$ to evaporate excess water and converting the solution to a viscous glassy gel. The gel was dried in an oven at $160^{\circ} \mathrm{C}$ and maintaining at this temperature overnight to produce dark greyish flakes. The flakes were ground and then calcined at $800^{\circ} \mathrm{C}$ for $4 \mathrm{~h}$ in box furnace with air atmosphere.

\subsection{Coating the LSMO nanoparticles with the silica shell}

Silica encapsulation process was performed according to the Stober method. ${ }^{26}$ First, the surface of the LSMO nanoparticles $(200 \mathrm{mg})$ was activated by sonication of nanoparticles in $1 \mathrm{M}$ nitric acid solution at room temperature for $15 \mathrm{~min}$. The nanoparticles were isolated by magnetic decantation using external magnet and redispersed in $0.1 \mathrm{M}$ citric acid solution and sonicated for another $15 \mathrm{~min}$. The nanoparticles were separated and washed with deionized water several times, and dispersed in water alkalized by adding some drops of ammonia solution.

The obtained solution was poured into a mixture of ethanol/water/ammonia with the final volume ratio of $70 / 28 / 2$. To encapsulate the nanoparticles by silica shell, $1 \mathrm{ml}$ TEOS was added to the reaction medium at $40^{\circ} \mathrm{C}$ with constant stirring. Finally, after $16 \mathrm{~h}$, the obtained product was separated by centrifugation and washed with ethanol and water and dried at $50^{\circ} \mathrm{C}$ for $24 \mathrm{~h}$.

\subsection{Characterization}

The X-ray diffraction (XRD) patterns of bare and silicacoated nanoparticles were obtained at room temperature by a Philips X'Pert powder diffractometer with $\mathrm{CuK} \alpha$ radiation and $\mathrm{Ni}$ filter $(\lambda=0.15418 \mathrm{~nm})$. Fourier transform infrared (FTIR) spectroscopy analysis was performed on a JASCO FTIR 680-Plus spectrometer in the region $400-4000 \mathrm{~cm}^{-1}$. The morphology and particle size distribution of nanoparticles were examined using a Zeiss-EM10C transmission electron microscope (TEM) operated at an acceleration voltage of $80 \mathrm{kV}$. The magnetic properties of sample were obtained by a vibrating sample magnetometer (VSM) instrument.

\subsection{Cell viability study through the methyl thiazol tetrazolium bromide (MTT) assay}

In vitro cytotoxicity of the bare and silica-coated LSMO nanoparticles was evaluated using MTT assay. To this end, approximately $1 \times 10^{5} \mathrm{ml}^{-1}$ cells (MCF-7) were seeded in a 96-well plate and incubated for $24 \mathrm{~h}$ at $37^{\circ} \mathrm{C}$ in a humidified $5 \% \mathrm{CO}_{2}$ atmosphere. The cells were treated with various concentrations $\left(50,100,200,400\right.$ and $\left.500 \mu \mathrm{g} \mathrm{ml}^{-1}\right)$ of bare and polymer-coated nanoparticles and were cultured for another $24 \mathrm{~h}$. After incubation, $15 \mu \mathrm{l}$ of MTT reagent was added to each well and was further incubated for $4 \mathrm{~h}$ and then optical density was evaluated at $570 \mathrm{~nm}$. Cell viability was calculated as follows:

$$
\begin{aligned}
\text { Cell viability }(\%) & =\left[\left(A_{\text {sample }}-A_{\text {blank }}\right) /\left(A_{\text {control }}-A_{\text {blank }}\right)\right] \\
& \times 100 \%,
\end{aligned}
$$

where $A_{\text {sample }}$ is the absorbance of a well containing cells, MTT solution, and bare or polymer-coated nanoparticles; $A_{\text {control }}$ the absorbance of a well containing cells and MTT solution only; and $A_{\text {blank }}$ the absorbance of a well containing medium and MTT solution only.

\subsection{Calorimetric measurements}

The heat generation ability of the silica-coated LSMO nanoparticles for biomedical application was investigated using a home-made induction heating instrument that induced an alternating magnetic field in five turns ( $5 \mathrm{~cm}$ diameter) induction coil. A close loop water temperature control was made to keep the temperature of the coil at ambient temperature. The stable suspension of silica-coated LSMO nanoparticles $\left(50 \mathrm{mg} \mathrm{ml}^{-1}\right)$ in $1.5 \mathrm{ml}$ plastic microtube, thermally insulated using styrofoam, was placed in the centre of coil and then irradiated by magnetic field ( $f=100 \mathrm{kHz}, H=10-20$ $\mathrm{kA} \mathrm{m}^{-1}$ ). The temperature of the sample was monitored by an alcohol thermometer. The value of the specific absorption rate (SAR) of the sample was calculated according to

$$
\mathrm{SAR}=\left(\frac{C_{\text {suspension }}}{X_{\mathrm{NP}}}\right)\left(\frac{\mathrm{d} T}{\mathrm{~d} t}\right),
$$


where $C_{\text {suspension }}$ is the specific heat of the suspension $\left(C_{\text {water }}=4.18 \mathrm{~J} \mathrm{~g}^{-1} \mathrm{~K}^{-1}\right.$ and $\left.C_{\mathrm{NP}}=0.66 \mathrm{~J} \mathrm{~g} \mathrm{~K}^{-1}\right),{ }^{27} X_{\mathrm{NP}}$ is the weight fraction of nanoparticles $\left(X_{\mathrm{NP}}=0.05\right)$ and $\mathrm{d} T / \mathrm{d} t$ is the initial slope of the temperature curve $v s$. time.

\section{Results and discussion}

Silica-coated magnetic nanoparticles can be synthesized by various synthetic methods, among which the two most common methods are sol-gel process and microemulsion method. ${ }^{26,28}$

The sol-gel method, known as the Stober method, used mainly for the synthesis of silica nanoparticles, is also applied for the formation of silica shell on the surface of magnetic nanoparticles. As an alternative to the Stober method, the microemulsion method has been used for the preparation of silica-coated iron oxide nanoparticles. ${ }^{29}$ Among these methods, the Stober method has been preferred more widely for synthesis of core-shell magneticsilica nanoparticles, because of low cost, relatively mild reaction condition, and surfactant-free. Hence, in this research, the coating process of the LSMO nanoparticles was performed according to the Stober's method using TEOS in highly polar mixtures of ethanol, water and ammonia.

\section{$3.1 X R D$}

Figure 1a shows the crystalline structure of bare and silicacoated LSMO nanoparticles examined by XRD analysis. In XRD pattern of bare nanoparticles, all reflection peaks can be well indexed with Joint Committee on Powder Diffraction Standards (JCPDS) (Card no.: 00-051-0409) and correspond to cubic perovskite structure (space group R-3C). ${ }^{30}$ No peak of any secondary or impurity phase is observed in the XRD pattern of bare nanoparticles, indicating the high purity of sample. When the LSMO nanoparticles were coated with silica, a broad band near $2 \theta \sim 24^{\circ}$ was detected, indicating the existence of amorphous $\mathrm{SiO}_{2}$ shell on the surface of nanoparticles. ${ }^{31}$ Also, the position of all reflection peaks on both XRD patterns remains similar, which demonstrates that the crystal structure of LSMO nanoparticles embedded in silica shell does not change after the coating process. Also, the average crystallite size $\left(D_{\mathrm{XRD}}\right)$ of LSMO nanoparticles was determined using Scherrer's equation:

$$
D=0.9 \lambda / \beta \cos \theta,
$$

where $\lambda$ is the incident X-ray wavelength $\left(\lambda_{\mathrm{Cu}}=1.5443 \AA\right)$, $\beta$ and $\theta$ the full-width at half-maximum (FWHM) and diffraction angle of the peak corresponding to maximum intensity, respectively. The average crystallite size of bare nanoparticles was calculated by applying equation (3) to the major reflection peak of XRD spectrum at $2 \theta=32.73^{\circ}$ and was about $48.8 \mathrm{~nm}$.

\subsection{FTIR analysis}

The crystalline structure of the LSMO perovskite oxides is similar to the distorted $\mathrm{GdFeO}_{3}$-type structure in which a central Mn cation is octahedrally surrounded by six oxygen onions. The $\mathrm{MnO}_{6}$ has nearly ideal octahedral symmetry with six vibrational modes, but only two of them are activated using IR irradiation. ${ }^{32}$ The band around $600 \mathrm{~cm}^{-1}$ is related to the stretching mode $\left(v_{\mathrm{s}}\right)$ of $\mathrm{Mn}-\mathrm{O}$ or $\mathrm{Mn}-\mathrm{O}-\mathrm{Mn}$ bonds, and the band around $400 \mathrm{~cm}^{-1}$ corresponds to the bending mode $\left(v_{\mathrm{b}}\right)$ of $\mathrm{Mn}-\mathrm{O}-\mathrm{Mn}$ bond, which is due to the change in the bond angle. ${ }^{33}$ The FTIR spectra of bare and coated LSMO nanoparticles are shown in figure 1b. In FTIR spectrum of uncoated nanoparticles, the absorption bands around 595 and $400 \mathrm{~cm}^{-1}$ can be observed, which are related to the stretching mode and bending mode of $\mathrm{Mn}-\mathrm{O}-\mathrm{Mn}$, respectively. The appearance of these bands suggests that the LSMO nanoparticles with perovskite structure have been formed at $800^{\circ} \mathrm{C}$, which is in agreement with XRD result.

In order to confirm the presence of the silica shell on the surface of LSMO nanoparticles, after coating process, FTIR analysis was performed on the obtained sample and the result is shown in figure $1 \mathrm{~b}$. Compared to the uncoated LSMO nanoparticles, some new absorption peaks have appeared in FTIR spectrum. The peaks at 468.3, 801.4 and $1085.5 \mathrm{~cm}^{-1}$

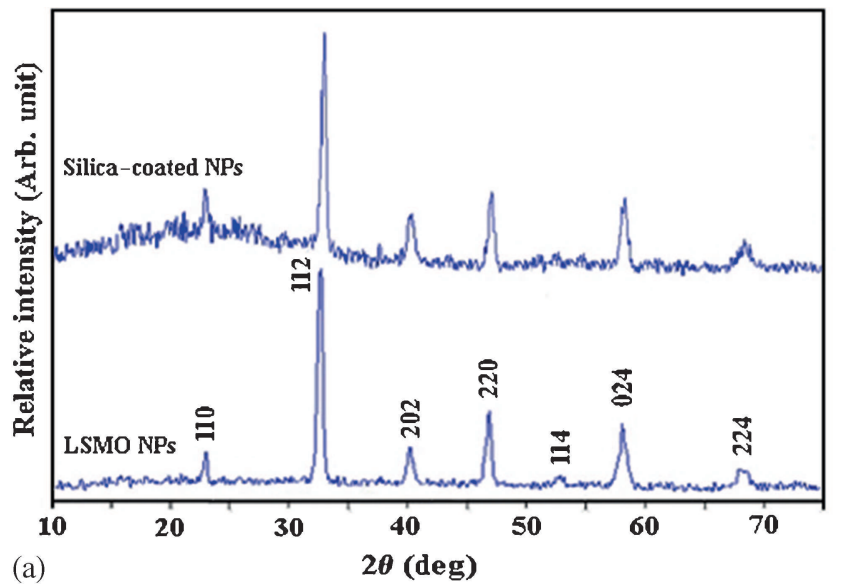

(a)

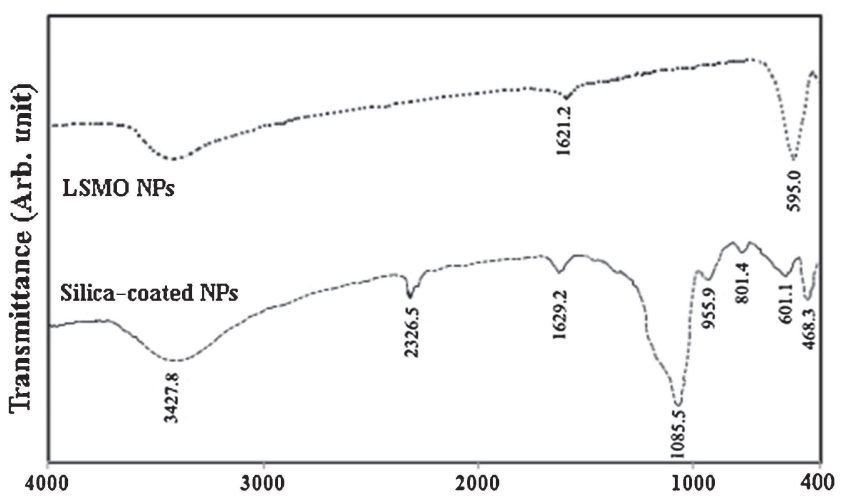

(b)

Wave number $\left(\mathrm{cm}^{-1}\right)$

Figure 1. (a) XRD patterns and (b) FTIR spectra of bare and silica-coated LSMO nanoparticles. 


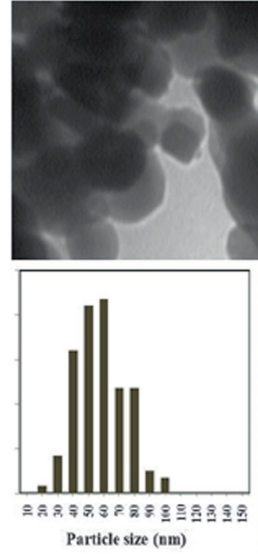

(a)

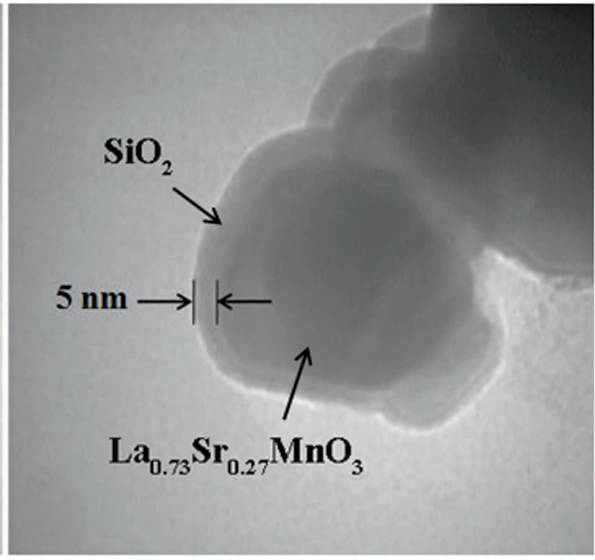

(b)

Figure 2. TEM images of (a) bare LSMO nanoparticles (inset shows particle size distribution) and (b) core-shell structure of silica-coated nanoparticles.

are assigned to the bending vibration, symmetric, and asymmetric stretching vibration of $\mathrm{Si}-\mathrm{O}-\mathrm{Si}$ bond, respectively. The appeared band at $955.9 \mathrm{~cm}^{-1}$ corresponds to the bending vibration of $\mathrm{Si}-\mathrm{OH}$. The absorption bands at around 1620 and $3427 \mathrm{~cm}^{-1}$ in two spectra are due to the stretching and bending modes of $\mathrm{H}-\mathrm{O}-\mathrm{H}$, free or adsorbed on the surface of nanoparticles, respectively. The characteristic absorption bands of LSMO nanoparticles also have appeared at $601.1 \mathrm{~cm}^{-1}$ in the spectrum of silica-coated LSMO nanoparticles but with smaller intensity. This can be explained by the fact that the surface of the nanoparticles is coated by thin $\mathrm{SiO}_{2}$ shell.

\subsection{TEM analysis}

Figure 2a shows TEM image of nanocrystalline LSMO synthesized at $800^{\circ} \mathrm{C}$. The inset of figure $2 \mathrm{a}$ shows the corresponding particle size distribution histogram of sample, which is calculated based on the Feret-diameter for more than 200 particles from several images. The average particles size distribution ( $\left.D_{\mathrm{TEM}}\right)$ is about $54 \mathrm{~nm}$ which is larger than the result obtained by Scherrer's equation, due to the attachment of crystalline primary particles during calcination process. ${ }^{34}$ Similar results have also been reported previously. ${ }^{35}$

The effect of particle size on the durability of MNPs in vivo has been investigated by several researchers. ${ }^{36,37}$ It has been found that particles with sizes in the range of $10-100 \mathrm{~nm}$ are optimal for long circulation times in vivo. Nanoparticles large than $200 \mathrm{~nm}$ are easily isolated by the macrophage cells or phacocytic cells in the spleen. ${ }^{36}$ Ultrasmall MNPs $(<10 \mathrm{~nm})$ are rapidly removed by the renal system. ${ }^{37}$ Hence, the nanoparticles obtained in this study with $54 \mathrm{~nm}$ average particle size are suitable for biomedical applications. The TEM image of silica-coated LSMO nanoparticles is shown in figure $2 \mathrm{~b}$. In this figure, the formation of core-shell structure

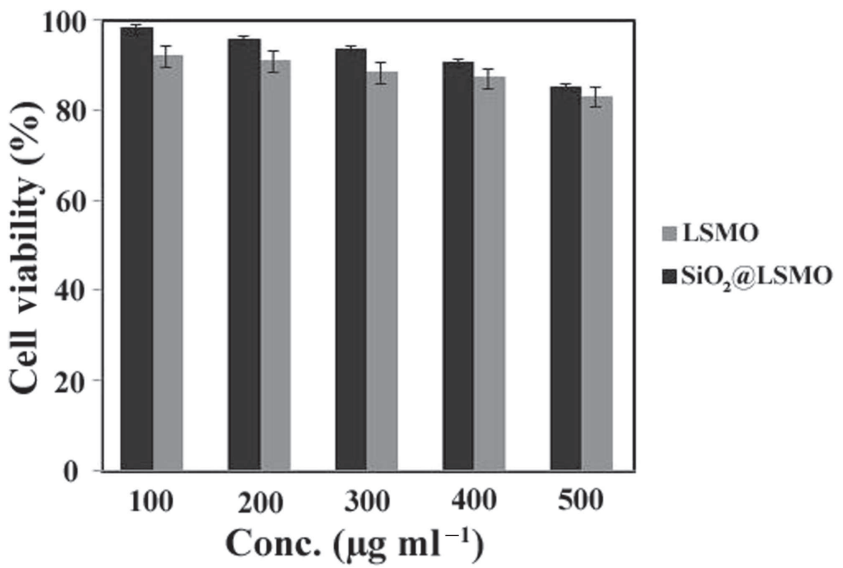

Figure 3. Cytotoxicity of bare and silica-coated LSMO nanoparticles at different concentrations.

can be confirmed by two distinguishable regions with different electron densities. A high electron density (darker) region is related to magnetic core and a transparent (low electron density) region surrounding core corresponds to the silica shell with thickness of about $5 \mathrm{~nm}$.

\subsection{Biocompatibility study}

The MTT assay was used to estimate the cytotoxicity of synthesized samples. Figure 3 shows the cell viability of MCF7 cells after $24 \mathrm{~h}$ exposure to the bare and silica coated nanoparticles at different concentrations (100, 200, 300, 400 and $500 \mu \mathrm{g} \mathrm{ml}^{-1}$ ). It can be clearly observed that the percent of cell viability depends on the concentration of nanoparticles in the cell culture media and decreased upon increasing nanoparticles concentration. Also, for the same concentration of samples, the polymer-coated nanoparticles is more biocompatible than the bare particles. For all concentrations, the values of the cell toxicity are less than $17 \%$. These results 


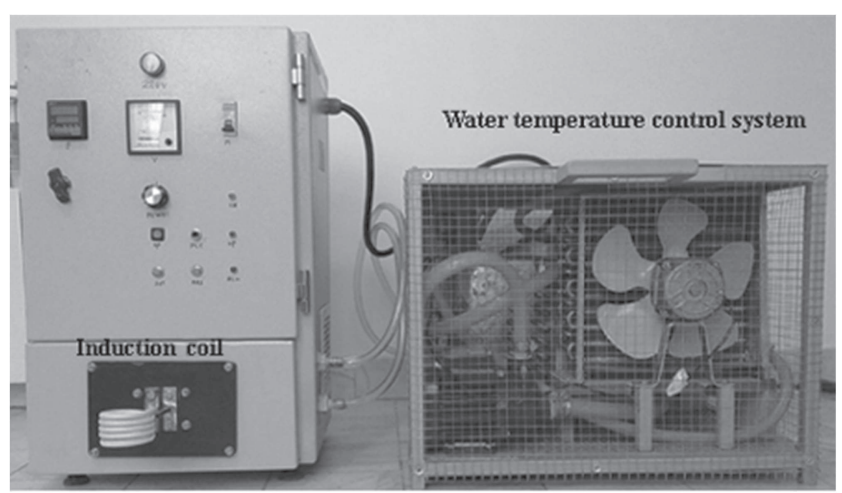

(a)

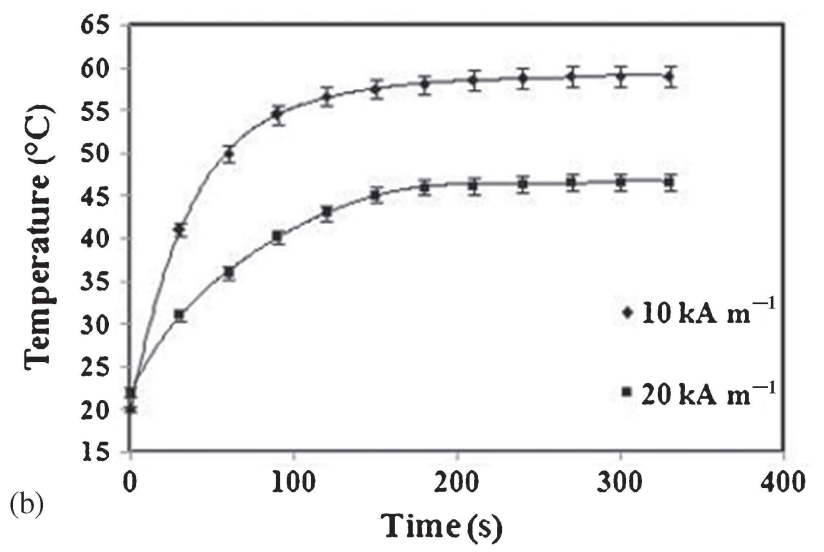

Figure 4. (a) Induction heating unit used for calorimetric measurement and (b) temperature vs. time for aqueous suspension of silica-coated LSMO nanoparticles at different magnetic fields.

indicate that the both prepared samples exhibit low cytotoxicity, satisfying one of the major requirements for biomedical applications.

\subsection{Magnetic properties}

Saturation magnetization $\left(M_{\mathrm{s}}\right)$ and the Curie temperature of bare LSMO nanoparticles, measured by the VSM method,

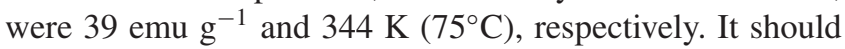
be remarked that this temperature corresponds to the complete demagnetization of sample and the maximum temperature achievable by nanoparticles exposed to a finite and specific magnetic field used in biomedical application should be determined by calorimetric measurements. The induction heating instrument used for calorimetric measurement is shown in figure $4 \mathrm{a}$. The temperature $v s$. heating time for aqueous suspension of silica-coated nanoparticles $\left(50 \mathrm{mg} \mathrm{ml}^{-1}\right)$ exposed to the alternating magnetic field with different intensities ( $H=10$ and $\left.20 \mathrm{kA} \mathrm{m}^{-1}, f=100 \mathrm{kHz}\right)$ are shown in figure $4 \mathrm{~b}$. As can be observed from figure $4 \mathrm{~b}$, after a short time (less than $3 \mathrm{~min}$ ), the temperature of suspension is saturated at $T_{\max }=46$ and $59^{\circ} \mathrm{C}$ for $H=10$ and $20 \mathrm{kA} \mathrm{m}^{-1}$, respectively. This saturation is due to the decreasing of the magnetization near the $T_{\mathrm{c}}$ and the balance of heat exchange with surrounding medium. Also, the heating curves show that the maximum temperature of magnetic suspension falls within the desired temperature range $\left(40-60^{\circ} \mathrm{C}\right)$ which suggests that the prepared samples are suitable for biomedical applications. In addition, the SAR values of samples were 47.3 and $77.8 \mathrm{~W} \mathrm{~g}_{\mathrm{NPs}}^{-1}$ for magnetic intensities of 10 and 20 $\mathrm{kA} \mathrm{m}^{-1}$, respectively.

\section{Conclusions}

Magnetic LSMO nanoparticles were successfully synthesized by the citrate-gel method. This synthesis technique resulted in nanoparticles with an average particle size of $54 \mathrm{~nm}$. The pure obtained nanoparticles were then successfully encapsulated with 5-nm-thick silica shell, employing a procedure derived from the Stober method. The formation of silica shell on the surface of nanoparticles was confirmed by XRD, FTIR and TEM analyses. Cytotoxicity of bare and silica-coated nanoparticles was evaluated by MTT assay with MCF-7 cell line. The results revealed that the both samples have negligible toxicity below $500 \mu \mathrm{g} \mathrm{ml}^{-1}$. Heating experiments at safe magnetic field $(f=100 \mathrm{kHz}$, $H=10-20 \mathrm{kA} \mathrm{m}^{-1}$ ) revealed that the maximum achieved temperature of water stable silica-encapsulated nanoparticles $\left(50 \mathrm{mg} \mathrm{ml}^{-1}\right)$ are fully in agreement with biomedical applications.

\section{References}

1. Mc Bain S C, Yiu H H and Dobson J 2008 Int. J. Nanomed. 3169

2. Tibbe A G J, de Grooth B, Greve J, Liberti P A, Dolan G J and Terstappen L W M M 1999 Nat. Biotechnol. 171210

3. Liberti P A, Rao C G and Terstappen L W M M 2001 J. Magn. Magn. Mater. 225301

4. Zhang M, Jugold E, Woenne T, Lammers B, Morgenstern M M, Mueller H, Zentgraf M, Bock M, Eisenhut M, Semmler W and Kiessling F 2007 Cancer Res. 671555

5. Elaissari A, Rodrigue M, Meunier F and Herve C $2001 \mathrm{~J}$. Magn. Magn. Mater. 225127

6. Jordan A, Scholz R, Wust P, Fahling H and Felix R 1999 J. Magn. Magn. Mater. 201413

7. Jordan A, Scholz R, Wust P, Schirra H, Schiestel T, Schmidt H and Felix R 1999 J. Magn. Magn. Mater. 194185

8. Soares P I, Ferreira I M, Igreja R A, Novo C M and Borges J P 2012 Rec. Patent Anticancer Drug Discov. 764

9. Purushotham S, Chang P E J, Rumpel H, Kee I H C, Ng R T H, Chow P K H, Tan C K and Ramanujan R V 2009 Nanotechnol. 20305101

10. Linh P H, Thach P V, Tuan N A, Thuan N C, Manh D H, Phuc N X and Hong L V 2009 J. Phys.: Conf. Ser. 187012069

11. Majeed J, Pradhan L, Ningthoujam R S, Vatsa R K, Bahadur D and Tyagi A K 2014 Colloid Surf. B 122396

12. Yu J H, Lee J S, Choa Y H and Hofmann H J 2010 Mater. Sci. Technol. 26333

13. Kuznetsov A A, Shlyakhtin O A, Brusentsov N A and Kuznetsov O A 2002 Eur. Cell. Mater. 375 
14. Asamitsu A, Morimoto $Y$, Kumai R, Tomioka $Y$ and Tokura $Y$ 1996 Phys. Rev. B 541716

15. Lu A H, Salabas E L and Schuth F 2007 Angew. Chem. Int. Ed. 461222

16. Sun C, Lee J S H and Zhang M 2008 Adv. Drug Deliv. Rev. 60 1252

17. Nasongkla N, Bey E, Ren J, Ai H, Khemtong C, Guthi J S, Chin S F, Sherry A D, Boothman D A and Gao J 2006 Nano Lett. 62427

18. Jeong U, Teng X, Wang Y, Yang H and Xia Y 2007 Adv. Mater. 1933

19. Laurent S, Forge D, Port M, Roch A, Robic C, Elst L V and Muller R N 2008 Chem. Rev. 1082064

20. Philipse A P, van Bruggen M P B and Pathmamanoharan C 1994 Langmuir 1092

21. Liu Q, Xu Z, Finch J A and Egerton R 1998 Chem. Mater. 10 3936

22. Liu X Q, Ma Z Y, Xing J M and Liu H Z 2004 J. Magn. Magn. Mater. 270

23. Soleymani M, Moheb A and Joudaki E 2009 Cent. Eur. J. Chem. 7809

24. Edrissi M, Soleymani M and Akbari S 2011 Synth. React. Inorg. M. 411282

25. Edrissi M, Hosseini S A and Soleymani M 2011 Micro. Nano Lett. 6836
26. Edrissi M, Soleymani M and Adinehnia M 2011 Chem. Eng. Technol. 341813

27. Kim D, Zink B L, Hellman F and Coey J M D 1994 Phys. Rev. B 65214424

28. Tago T, Harsuta T, Miyajima K, Kishida M, Tashiro S and Wakabayashi K 2002 J. Am. Ceram. Soc. 85 2188

29. Narita A, Naka K and Chujo Y 2009 Colloids Surf. A 336 46

30. Sayagues M J, Cordoba J M and Gotor F J 2012 J. Solid State Chem. 18811

31. Singh R K, Kim T H, Patel K D, Knowles J C and Kim H W 2012 J. Biomed. Mater. Res. A 100A 1734

32. Liu Sh, Tan X, Li K and Hughes R 2002 Ceram. Int. 28327

33. Wang X, Cui Q, Pan Y and Zou G 2003 J. Alloys Compd. 35491

34. Naravanaswamy A, Xu H F, Pradhan N and Peng X G 2006 Angew. Chem. Int. Ed. 455361

35. Lopez-Quintela M A, Hueso L E, Rivas J and Rivadulla F 2003 Nanotechnol. 14212

36. Tabata Y and Ikada Y 1990 Adv. Polym. Sci. 94107

37. Choi H S, Liu W, Misra P, Tanaka E, Zimmer J P, Ipe B I, Bawendi M G and Frangioni J V 2007 Nat. Biotechnol. 251165 